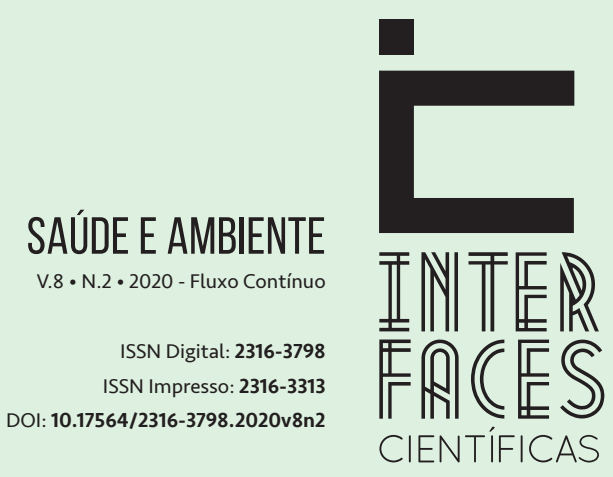

\section{COVID-19: UM PANORAMA COM ÊNFASE EM MEDIDAS RESTRITIVAS DE CONTATO INTERPESSOAL}

COVID-19: AN OUTLOOK WITH EMPHASIS ON RESTRICT MEASURES OF INTERPERSONAL CONTACT

COVID-19: UN PANORAMA CENTRADO EN MEDIDAS RESTRICTIVAS DE CONTACTO INTERPERSONAL

\section{RESUMO}

Buscou-se oferecer uma visão geral da pandemia de COVID-19, enfatizando os impactos das medidas de saúde pública restritivas de contato interpessoal propostas pela OMS. Desenvolveu-se pesquisa exploratória, a partir da revisão sistemática de artigos de grande impacto internacional nas ciências médicas, publicados após a decretação pela OMS da COVID-19 como Emergência de Saúde de Âmbito Internacional, em janeiro de 2020. Além disso, buscou-se discutir a problemática gerada por governantes, ao contrariarem as propostas da OMS para interrupção da transmissão. Assim, foi possível reunir e apresentar informações atualizadas sobre a COVID-19 e, principalmente, reconhecer o papel inequívoco no controle da pandemia pelas medidas clássicas de saúde pública.

\section{PALAVRAS-CHAVE}

Coronavírus. Quarentena. Pandemia 


\section{ABSTRACT}

It sought to provide an overview of the Covid-19 pandemic, emphasizing the impacts of restrictive interpersonal contact as public health measures, proposed by WHO. Exploratory research was developed, based on the systematic review of great international impact articles in the medical sciences published after the decree International Health Emergency for COVID-19, by WHO in January 2020. In addition, an attempt was made to discuss a problem generated by government officials, as opposed to the WHO proposals to interrupt transmission. Thus, it was possible to gather and present updated information on COVID-19 and, above all, to recognize the unequivocal role in controlling the pandemic by classical public health measures.

\section{KEYWORDS}

Coronavirus.Quarantine. Pandemic

\section{RESÚMEN}

Se buscó proporcionar una visión general de la pandemia de COVID-19, enfatizando los impactos de medidas de salud pública restrictivas de contacto interpersonal, propuestas por la OMS. Se llevó a cabo una investigación exploratoria, basada en la revisión sistemática de artículos de gran impacto internacional en las ciencias médicas, publicados después del decreto de la OMS de COVID-19 como Emergencia Internacional de Salud en enero de 2020. Además, se intentó discutir el problema generado por los funcionarios del gobierno, al contradecir las propuestas de la OMS para interrumpir la transmisión. Por lo tanto, fue posible recopilar y presentar información actualizada sobre COVID-19 y, principalmente, reconocer el papel inequívoco en el control de la pandemia con medidas clásicas de salud pública.

\section{PALABRAS CLAVE}

Coronavirus.Cuarentena. Pandemia 


\section{INTRODUÇ̧̃̃o}

Ainda no final de 2019, um número cada vez maior de pacientes com sintomas de grave insuficiência respiratória chegou aos serviços de saúde da cidade de Wuhan, Província de Hubei, China. A partir de amostras de fluido bronquioalveolar desses pacientes, em 3 de janeiro de 2020, foi identificado 0 genoma completo do 2019-nCoV, um novo coronavírus.

Também em janeiro, com o incremento no número de casos e o surgimento de outros focos da denomina COVID-19, o Comitê de Vigilância Internacional para as Doenças Transmissíveis da Organização Mundial da Saúde (OMS) decretou Emergência de Saúde de Âmbito Internacional. Com isso, um grande esforço mundial passou a ser desenvolvido, buscando maior conhecimento clínico da patologia, mais rápidos e precisos métodos de diagnóstico e, sobretudo, de um tratamento farmacológico e imunoprevenção.

Contudo, uma vez que o tratamento disponível é apenas sintomático, com ação principalmente sobre sintomas iniciais da COVID-19, e com a ausência de uma vacina, restou a aplicação de medidas clássicas de saúde pública. Essas medidas visam impedir a propagação da doença, interrompendo a transmissão do vírus por meio da restrição do contato interpessoal. Entre as práticas adotadas estão a quarentena, o isolamento e a contenção social.

É claro que medidas restritivas como estas, a despeito de serem necessárias e propostas terminantemente pela OMS, geram discussões éticas e legais e acarretam desequilíbrio na economia e na sociedade em geral. Assim, apesar de se observarem exemplos de seguimento radical das diretrizes da OMS, também há líderes políticos que relutam e minimizam essas diretrizes, colocando a vida de toda a população em risco. Essa postura tem acarretado embates entre o governo federal brasileiro e vários governos estaduais.

Assim, o objetivo do trabalho é apresentar um panorama atual sobre a COVID-19 e trazer luz para a discussão, que se prolonga no Brasil, quanto à aplicação de medidas clássicas de saúde pública relacionadas à restrição do contato interpessoal. Para tanto, desenvolveu-se pesquisa exploratória e qualitativa, a partir de documentação indireta de fontes secundárias como artigos e sites. Esta pode ser configurada como uma revisão sistemática dos trabalhos publicados ou, face à urgência do tema, ainda no prelo, disponibilizados principalmente entre janeiro e abril de 2020 por revistas internacionais de grande impacto na área médica e científica.

\section{COVID-19 [SARS-COV-2]}

Já em meados de novembro de 2019, um número importante de pessoas da Província de Hubei, na China, buscou os serviços de saúde com quadros graves de insuficiência respiratória. De fato, tratava-se de um quadro agudo de insuficiência respiratória, com demanda de ventilação mecânica, de pessoal especializado e de ações emergenciais para o isolamento de assintomáticos e bloqueio da região. Ainda assim, muitas pessoas realizaram, até início de fevereiro de 2020, viagens em função das comemorações do Ano Novo Chinês, deflagrando inúmeros focos da nova doença. 
O agente etiológico da síndrome que surgia, chamada à época SARS-CoV-2, era um novo coronavírus (2019-nCoV). Os coronavírus são conhecidos desde a década de 1960 e originalmente, causavam patologias respiratórias com sintomas de resfriado. Em 2003, contudo, representantes dessa família de vírus geraram um significativo número de casos da síndrome respiratória aguda grave (SARS-CoV), considerada uma doença emergente (WU et al., 2020).

Ainda em 3 de janeiro de 2020, foi identificado o genoma completo do 2019-nCoV a partir da amostra de fluido bronquioalveolar de um paciente de Wuhan (TAN et al., 2020). Em 30 de janeiro de 2020, o Comitê de Vigilância Internacional para as Doenças Transmissíveis da OMS reconheceu os critérios para decretar uma Emergência de Saúde de Âmbito Internacional relacionada à doença que recebeu definitivamente a denominação de COVID-19 (WHO, 2020a e 2020b).

A COVID-19 apresenta uma ampla sintomatologia, variando de uma infecção respiratória leve à aguda grave. Entre os sinais e sintomas detectados, Denis e colaboradores (2020) conseguiram reunir os seguintes: febre, tosse, dispneia, mialgia, fadiga, confusão mental, dor de cabeça, dor de garganta, rinorreia, dor no peito, diarreia, náusea, vômito e síndrome do desconforto respiratório agudo. Os três primeiros são os mais comumente relatados e os demais se encontram descritos em ordem de frequência. No entanto, pacientes hospitalizados podem apresentar diferentes graus de cada um deles (DENIS et al., 2020). Outro sintoma que vem sendo cada vez mais relatado é a alteração e até perda do olfato e paladar (BRANN et al., 2020).

O diagnóstico tem sido feito por meio da observação dos sintomas, que, no entanto, são comuns a outras síndromes respiratórias (CHEN, G. et al., 2020). A piora no prognóstico pode ser monitorada com o auxílio de imagens pulmonares em tomografia computadorizada similares a vidro fosco (GUAN et al., 2020). Além disso, laboratorialmente, pode ser observada redução na contagem de linfócitos (CHEN, G. et al., 2020) e eosinófilos (LI, Q. et al., 2020a); elevação da proteína C reativa (ZHANG, J. et al., 2020); e alterações nos parâmetros de coagulação e nas dosagens bioquímicas, como da albumina, lactato desidrogenase e angiotensina II, que mostra elevação associada à carga viral e à lesão pulmonar (LIU et al., 2020). Contudo, a certeza da infecção pelo 2019-nCoV é possível, logo no início, pelo teste molecular de RT-PCR (Reação em Cadeia da Polimerase-Transcriptase Reversa). A resposta imune ao vírus pode ser detectada pelos testes rápidos de IgM, imediatamente após a janela imunológica (3-6 dias), e IgG, mais tardiamente (oito dias), como resposta aparentemente protetora (LI, Z. et al., 2020).

A taxa de mortalidade parece crescer rapidamente em pacientes com idade superior a 50 anos (1,3\%), alcançando 14,8\% em pacientes maiores de 80 anos, independentemente de comorbidades. Contudo, não se pode desconsiderar a possibilidade de evolução letal em pacientes mais novos (NOVEL CORONAVIRUS PNEUMONIA EMERGENCY RESPONSE EPIDEMIOLOGY TEAM, 2020).

$\mathrm{Na}$ maioria dos casos de óbito, observavam-se comorbidades $(76,8 \%)$, incluindo hipertensão $(56,1 \%)$, doença cardíaca $(20,7 \%)$, diabetes (18,3\%), doença cerebrovascular (12,2\%) e câncer (7,3\%) (FENG et al., 2020). A associação com doença cardíaca pode ter ainda maior importância, pois se verificou em pacientes hospitalizados de Wuhan lesões no coração provocadas pelo vírus (SHI et al., 2020). 
Como muitos outros vírus que provocam sintomas respiratórios, o coronavírus tem predileção por este sistema. 0 2019-nCoV parece colonizar em alto grau as vias superiores. Assim, as observações sugerem transmissão através aerossolização de vírus em espaço confinado ou no ambiente próximo a pessoas infectadas, sintomáticas ou não, e ainda pelo contato a objetos contaminados (CAl et al., 2020). Deve-se atentar que, mesmo após alguns dias da recuperação, observou-se material genético do vírus em pacientes, sendo possível a transmissão (LAN et al., 2020).

Inicialmente, preconizou-se que o vírus, semelhante ao que ocorreu na SARS-Cov, seria disperso apenas através de gotículas grandes que logo se depositariam nas superfícies (WILDER-SMITH; FREEDMAN, 2020), mas foi determinado que o agente pode permanecer viável e infeccioso em aerossóis por até três horas e em superfícies, como plástico, vidro, aço inoxidável, cobre e papelão, por até três dias (DOREMALEN et al., 2020). Apesar do novo coronavírus persistir em superfície, é inativado pela limpeza com álcool (62-71\%), peróxido de hidrogênio $(0,5 \%)$ ou hipoclorito de sódio $(0,1 \%)$ (KAMPF et al., 2020). Para a antissepsia, especialmente de mãos e antebraços, água e sabão parecem ser suficientes.

Já foram encontrados vírus em descargas oculares de um paciente com conjuntivite, embora o sintoma seja raro na COVID-19. Assim, os autores sugeriram uma via potencial de infecção nosocomial (SUN et al., 2020).

Zhang, W. e colaboradores (2020) também relataram a detecção de vírus em swabs anais, principalmente em estágios mais tardios da doença. Xiang e colaboradores (2020) encontraram vírus nas fezes de metade dos pacientes coronavírus positivo. A transmissão fecal pode ser apoiada pela diarreia encontrada em pacientes antes do desenvolvimento de febre e dispneia (WANG et al., 2020). A transmissão vertical (mãe-filho) não parece acontecer (CHEN, H.C. et al., 2020). Provavelmente aconteceria transmissão através de produtos sanguíneos não testados (CHANG et al., 2020).

Quanto ao tratamento, muitas pesquisas vêm sendo realizadas em busca de um medicamento contra o vírus (LU, 2020). Vários fármacos anti-retrovirais, como os já utilizados contra HIV/AIDS e outras patologias, já foram propostos. São exemplos desses medicamentos com aplicação divergente daquela especificada em bula off-label, os inibidores da entrada de vírus na célula hospedeira, p.ex. cloroquina; inibidores da RNA polimerase, que impossibilitam a replicação do material genético do vírus; inibidores de protease, que impedem a construção do complexo de replicação viral. Os sintomas iniciais podem ser manejados com o uso de anti-inflamatórios não esteroidais. Contudo há discussão quanto à utilização especificamente do Ibuprofeno e possível piora do caso (DENIS et al., 2020).

Da mesma forma, a busca por imunoprevenção tem estimulado muitas pesquisas e sido acompanhada pela OMS (WHO, 2020b). Apesar da alguma homologia de sequência entre SARS-CoV-2, SARS-CoV e, em menor grau, MERSCoV, não se espera que candidatos à vacina desenvolvidos contra estes outros coronavírus gerem níveis adequados de reação para o 2019-nCoV, demandando vacinas com antígenos específicos. Há relato de que dois meses após o surto de SAR-CoV-2, pelo menos 37 empresas biofarmacêuticas ou setores acadêmicos estavam na corrida para desenvolver uma vacina por meio de mRNA, DNA, vetor adenoviral e proteína recombinante (PROMPETCHARA et al., 2020). 
Por outro lado, a ideia de um soro contendo imunoglobulina obtida de convalescentes tem ganhado força como tratamento da doença, de certo modo, remontando terapêuticas do séc. XIX (CASADEVALL; PIROFSKI, 2020).

Assim, na ausência de vacinas para a prevenção ou de uma terapêutica farmacológica adequada à cura, o enfrentamento ao surto de Coronavírus, causador da COVID-19, tem requerido medidas clássicas de saúde pública. Entre essas práticas, encontramos a quarentena, o isolamento e a contenção social, as quais têm como função impedir a propagação da doença entre pessoas, interrompendo a transmissão do vírus (WILDER-SMITH; FREEDMAN, 2020).

\section{RESTRIÇÃO DO CONTATO INTERPESSOAL}

Certamente, apesar de ações de restrição de contato interpessoal remontarem a Grécia Antiga (SANTOS; NASCIMENTO, 2014), nunca antes foram utilizadas em tão larga escala. Contudo, medidas clássicas de saúde pública como as descritas, uma vez que restringem a locomoção e o contato entre pessoas geram questões éticas complexas. Assim, alguns pesquisadores, partindo da análise do surto de SARS, propuseram a ética da quarentena (SINGER et al., 2003). Esta é baseada fundamentalmente em cinco valores éticos: o primeiro é a liberdade individual, que mesmo sendo o mais alto valor, deve ser equilibrado com o segundo valor, a proteção coletiva. Estes devem ser sopesados pelo terceiro, a proporcionalidade, de forma que os poderes públicos só devam propor tais limitações se realmente foram relevantes, legítimas e necessárias. Dessa forma, devem usar o mínimo de métodos restritivos, razoavelmente e sem discriminação.

O quarto valor seria a transparência, exigindo que as partes interessadas sejam plenamente informadas sobre questões que propiciara as medidas tomadas, incluindo os riscos e benefícios. Atualmente, o combate às notícias falsas, deve ser levado em conta nesse valor. Finalmente, deve-se considerar o valor da reciprocidade. Para a implementação deste, deve-se exigir que se garanta aos afastados do convívio atendimento adequado e que não sofram sanções econômicas injustas (SINGER et al., 2003).

Na definição de cada medida, passamos a analisar o "isolamento". Este deve ser entendido propriamente como separação. Nessa medida, as pessoas com doenças contagiosas são segregadas daquelas não infectadas. Na verdade, é possível distinguir o isolamento para impedir a transmissão daquele chamado isolamento protetor ou reverso. Neste, o paciente imunossuprimido e imunodeprimido é isolado para evitar sua exposição a condições contaminantes (GOLDIM, 2020).

Santos e Nascimento (2014) informam que há na literatura quem defina isolamento como prisão domiciliar de doentes, mas os próprios autores o definem como confinamento de pessoas sob tratamento de saúde em meio hospitalar. Assim, a despeito de poder haver o isolamento domiciliar, geralmente, essa medida ocorre em um hospital ou instituição na qual se possa manter o controle e o tratamento individual. Há acompanhamento por profissionais de saúde que devem utilizar EPIs (equipamentos de proteção individual) e EPCs (equipamentos de proteção coletivos), além de seguir protocolos de segurança que resguardem a todos (GOLDIM, 2020; WILDER-SMITH; FREEDMAN, 2020). 
Deve-se atentar, todavia, ao fato de que o isolamento ganha eficiência, quando ocorre a detecção precoce do vírus, antes do derramamento viral, pois nessa fase o vírus está circulante no paciente e este pode transmiti-lo, mesmo sem sintomas clínicos. No caso da COVID-19, o tempo de incubação se encontra entre 5,1 e 5,2 dias, sendo que mais de $95 \%$ dos casos desenvolveram sintomas da infecção em até 12,5 dias. Estes dados são similares ao período de incubação do SARS e maior do que o período observado na influenza (LAUER et al., 2020; LI, Q. et al., 2020b).

Assim, o derramamento viral do 2019-nCoV acaba por ser muito grande e o isolamento, em geral, ocorre tardiamente (WILDER-SMITH; FREEDMAN, 2020). Na verdade, as características epidemiológicas mais agressivas da SARS-Cov-2 surgem de fatores como altas cargas virais no trato respiratório superior e do potencial de pessoas infectadas eliminarem e transmitirem o vírus enquanto assintomático (DOREMALEN et al., 2020).

A quarentena, por sua vez, também remonta práticas antigas para contenção eficaz de surtos de doenças (WILDER-SMITH; FREEDMAN, 2020). Contudo, não está claro o motivo para a determinação do período de 40 dias. Há quem entenda tratar-se de uma relação com o tempo da Quaresma, representando uma forma de purificação espiritual; outros acham que a detenção de 40 dias não se baseou em superstição, mas em observação médica (KILWEIN, 1995).

Quando se busca na história, o período mais marcante de utilização deste método é encontrado no séc. XIV, no porto de Veneza, Itália. Nesse período, Europa e Ásia passaram pela maior e mais trágica epidemia que a história registra (REZENDE, 2009), na qual morreram centenas de milhões de pessoas. Quem chegava ao porto italiano, oriundo de portos infectados, era obrigado a ancorar e aguardar 40 dias até o desembarque dos sobreviventes (WILDER-SMITH; FREEDMAN, 2020).

As primeiras conferências internacionais a discutirem as técnicas de quarentena ocorreram a partir de 1851. As decisões científicas produzidas nesses encontros passaram a fundamentar as normas internacionais sobre o assunto, em especial no que diz respeito ao controle da cólera, febre amarela, direcionadas especialmente às migrações e viagens. A organização das diversas decisões e recomendações sobre qua-

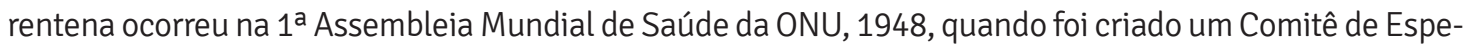
cialistas em Epidemiologia e Quarentena Internacional. Um texto final foi aprovado em 1951, com o apoio de especialistas dos Estados membros (SANTOS; NASCIMENTO, 2014). Vale destacar que em um contexto legal, p.ex. nos EUA, o termo quarentena refere-se a praticamente todas as práticas de saúde pública por restrição de contato, como o isolamento ou a limitação de viagens (PARMET; SINHA, 2020).

Objetivamente, a quarentena busca restringir a circulação de pessoas presumivelmente expostas a um agente contagioso. 0 sujeito que é posto em quarentena não está necessariamente doente, mas devido ao período de incubação do agente etiológico, não seria possível determinar em princípio se foi infectado (WILDER-SMITH; FREEDMAN, 2020). Esta prática de restrição pode ser tomada de forma voluntária ou obrigatória, individualmente ou de forma coletiva. No decorrer do período de contenção, os submetidos devem ser monitorados em busca da detecção de sinais e sintomas da doença, pois, ao surgirem, levariam ao isolamento. Como, de acordo com os achados clínicos, o período de incubação da COVID-19 está em torno de cinco dias, tem sido praticada, por precaução, uma quarentena de 14 dias (LAUER et al., 2020; LI, Q. et al., 2020). 
Da mesma forma que no isolamento, a detecção rápida da doença é importante para o sucesso da quarentena. Outro ponto importante para o sucesso desse tipo de contenção é a efetividade do rastreamento da cadeia de transmissão e de outros dados epidemiológicos que apontem para a possibilidade de contágio (WILDER-SMITH; FREEDMAN, 2020). Assim, ainda haveria inconsistências sobre a efetividade pública da quarentena (SANTOS; NASCIMENTO, 2014).

O distanciamento ou contenção social tem o propósito de reduzir interações em grupos maiores, que pode ser feito, por meio do fechamento de escolas, escritórios, shoppings, redução de meios de transportes. Neste grupo podem ser encontradas pessoas infectadas, mas ainda não identificados e, portanto, ainda não isoladas. Em geral, tendo em vista a necessária proximidade entre as pessoas para a transmissão efetiva ou o contato com superfícies contaminadas, o distanciamento tem bons resultados (WILDER-SMITH; FREEDMAN, 2020).

Quando necessário o aumento nos limites de contenção social, alcançando restrição de entrada e saída de bairros, cidades, estados e até países, deve-se garantir que os meios vitais possam ser acessados. Nesses casos, chamado de isolamento horizontal, as questões éticas e relacionadas aos direitos humanos e economia são muito mais complexas. O uso responsável das mídias, atuando sobre as fake news, é essencial para que toda a população tenha a correta dimensão do problema e das ferramentas que estão sendo usadas no atendimento dos doentes e métodos de prevenção. Para tanto, deve haver uma atuação coordenada de autoridades policiais e sanitárias em todos os níveis de governo, com, p.ex., o estabelecimento de postos de checagem (WILDER-SMITH; FREEDMAN, 2020).

A efetiva contenção social deve ser acompanhada de normatização robusta e, por vezes, com penalidades que podem ser gravosas contra os que a violem. É preciso, no entanto, que se busque sempre garantir os direitos humanos e a ética, pois é certo que, nesta condição extraordinária, voltar-se-á à proteção da coletividade em detrimento das liberdades individuais, estabelecendo a supremacia do princípio utilitarista (SANTOS; NASCIMENTO, 2014).

Deve-se atentar para que essas ações não se transformem em mero exercício de "biopoder" (GOLDIM, 2020). Santos e Nascimento (2014) alertam que o uso do poder sitiante do Estado [...], daria suporte a práticas inespecíficas de Estado de Exceção (p.183), já tendo sido utilizado por regimes governamentais autoritários [...] (p.175).

De toda forma, na atual pandemia de Coronavírus, são as práticas clássicas em Saúde Pública, pela restrição do contato interpessoal, que trouxeram algum alento. Apesar de não ser possível dizer que o vírus foi erradicado, a supressão do agente infectante está evidente na China, epicentro da pandemia (CYRANOSKI, 2020). Os resultados já mostram que a intervenção combinada, com quarentena, fechamento de escola e de locais de trabalho e distanciamento social foi o mais eficaz, do que a nenhuma intervenção (LEWARD; LO, 2020).

De acordo com a Revista Nature, antes das ações restritivas de contato, calculava-se que cada infectado transmitiria o vírus para outras oito pessoas, de forma que $40 \%$ da população chinesa (500 milhões de pessoas) seriam infectadas. Após sete dias da implantação das medidas, o número de infectados, a partir de um transmissor, caiu para 1,05 (CYRANOSKI, 2020). A partir 
da experiência exitosa chinesa, foi possível determinar que as restrições de viagem são particularmente úteis na fase inicial de um surto, quando ainda está confinado a uma determinada área fonte, perdendo eficácia quando o surto for disseminando-se. Reconhece-se, no entanto, que mais análises são necessárias para se alcançar melhor equilíbrio entre o efeito positivo de saúde pública e o impacto negativo na liberdade de movimento, na economia e na sociedade em geral (KRAEMER et al., 2020).

Tomando esse exemplo, muitos países e territórios menores estão propondo medidas semelhantes. Contudo, a eficácia e o impacto social dessas medidas parecem depender da credibilidade do público em suas autoridades de saúde, líderes políticos e instituições. Essa confiança pública é obtida quando as intervenções são transparentes e baseadas em evidências científicas e a comunicação está firmada em fatos (LEWARD; LO, 2020).

De forma geral, a pandemia tem propiciado uma grande rede de solidariedade que vai de vizinhos a países. Compartilha-se desde conhecimento científico sobre a pandemia, medicamentos, insumos e equipamentos de uso médico, até o mais necessário, alimento, material de limpeza e higiene pessoal para os mais vulneráveis (THE LANCET, 2020).

Por outro lado, a fraca resposta de alguns líderes tem gerado de acordo com o editorial do renomado periódico médico The Lancet, “medo, raiva, incerteza e desconfiança”. Enquanto, muitos governos nacionais responderam rapidamente à ameaça da COVID-19, outros ainda não reconheceram o problema e relutam a acompanhar as determinações da OMS. Esse é o exemplo do Brasil, onde o presidente Jair Bolsonaro tem sido "fortemente criticado por especialistas em saúde e enfrenta uma reação pública intensificada pela sua fraca resposta"(THE LANCET, 2020, p.1011). 0 presidente brasileiro tem considerado radicalismo as ações generalizadas de restrição de contato, inclusive atacando medidas decretadas por governadores dos estados. 0 presidente acredita, diferente de tudo que já fora apresentado, que o isolamento vertical, voltada para grupos de risco, como idosos e portadores de doenças crônicas, já seria suficiente frente à disseminação da pandemia (GULLINO, 2020).

\section{CONCLUSÃO}

Enquanto escrevemos essa conclusão, o Worldometer aponta que a COVID-19 já alcançou cerca de 1,3 milhões de pessoas em 208 países e territórios e as mortes ultrapassaram 70 mil (WORLDOMETER, 2020). Apesar de algumas projeções matemáticas, ninguém pode prever até onde o novo coronavírus pode chegar. Por outro lado, a única certeza é que se trata de uma das maiores pandemias pela qual a humanidade já passou e que, na falta de terapêutica farmacológica e imunoprevenção, a humanidade tem sua salvaguarda nas medidas clássicas de saúde pública, a partir da restrição do contato interpessoal.

0 ataque à COVID-19 demanda o empenho de todos: dos pesquisadores em busca de tratamentos e prevenção; de industriais, produzindo os insumos clínicos, de diagnóstico e de proteção; dos profissionais de saúde, segurança, produtores de alimentos e demais trabalhadores de serviços essenciais; mas, sobretudo, daqueles que colaboram com os mais vulneráveis. Uma espécie de isolamento solidário. 
Também está claro que não é colocando em dúvida os dados científicos e nem menosprezando a COVID-19 ou ridicularizando os doentes que vamos contribuir na luta contra a pandemia. A manutenção da economia dos países é importante, mas não haverá economia sem pessoas e a informação fidedigna precisa chegar aos cidadãos que devem poder confiar em seus líderes.

\section{REFERÊNCIAS}

BRANN, D.H. et al, Non-neural expression of SARS-CoV-2 entry genes in the olfactory epithelium suggests mechanisms underlying anosmia in COVID-19 patients. bioRxiv 2020.03.25.009084, 2020. doi: https://doi.org/10.1101/2020.03.25.009084

CAI, J. et al Indirect Virus Transmission in Cluster of COVID-19 Cases, Wenzhou, China, Emerg Infect Dis. v. 26, n. 6, june 2020. doi: https://doi.org/10.3201/eid2606.200412

CASADEVALL, A.; PIROFSKI, L-a. The convalescent sera option for containing COVID-19. J. Clin Invest. v. 130, n. 4, p. 1545-1548, 2020. doi: https://doi.org/10.1172/JCl138003

CHANG, L. et al. Coronavirus Disease 2019: Coronaviruses and Blood Safety. Transfus Med Rev. in press. Feb 21, 2020. doi: https://doi.org/10.1016/j.tmrv.2020.02.003

CHEN, G. et al. Clinical and immunologic features in severe and moderate forms of Coronavirus Disease 2019. medRxiv. 2020.02.16.20023903, 2020. doi: https://doi. org/10.1101/2020.02.16.20023903

CHEN, H.C. et al. Clinical characteristics and intrauterine vertical transmission potential of COVID-19 infection in nine pregnant women: a retrospective review of medical records. The Lancet. v. 395, n. 10226, p. 809-815, 2020. doi: https://doi.org/10.1016/S0140-6736(20)30360-3

CYRANOSKI, D. What China's coronavirus response can teach the rest of the world. Nature. v. 579, p. 479-480, 2020. doi: 10.1038/d41586-020-00741-x.

DENIS, M. et al. Overview of information available to support the development of medical countermeasures and interventions against COVID-19. 23 mar 2020. Transdiscipl Ins - Living Paper. v. apr 6, 2020.

DOREMALEN, N. et al. Aerosol and Surface Stability of SARS-CoV-2 as Compared with SARS-CoV-1. N. Engl. J. Med. Letters 2020 mar 17; doi: https://doi.org/10.1056/NEJMc2004973 
FENG, Z. et al. The Novel Coronavirus Pneumonia Emergency Response Epidemiology Team. The Epidemiological Characteristics of an Outbreak of 2019 Novel Coronavirus Diseases (COVID-19). China CDC Weekly. v. 2, n. 8, p. 113-122, 2020. doi: https://doi.org/10.3760/cma.j.is sn.0254-6450.2020.02.003

GOLDIM, J.R. COVID-19, Isolamento, Quarentena e Confinamento. Disponível em: https:// bioeticacomplexa.blogspot.com/. Acesso em: 17 mar 2020.

GUAN, W.J. et al., China Medical Treatment Expert Group for Covid-19. Clinical Characteristics of Coronavirus Disease 2019 in China. N Engl J Med. 2020 Feb 28. doi: https://doi.org/10.1056/ NEJMoa2002032

GULLINO, D. Bolsonaro critica decreto de Witzel: ‘Parece que o Rio de Janeiro é outro país'. 0 Globo. 20 mar. 2020. Disponível em: https://oglobo.globo.com/rio/bolsonaro-critica-decreto-de-witzelparece-que-rio-de-janeiro-outro-pais-24317498. Acesso em: 21 mar 2020.

KAMPF, G. et al. Persistence of coronaviruses on inanimate surfaces and its inactivation with biocidal agents. J Hosp Infect. v. 104, n. 3, p. 246-251, 2020. doi: https://doi.org/10.1016/j. jhin.2020.01.022

KILWEIN, J.H. Some historical comments on quarantine: Part One. J Clin Pharm Ther. v. 20, n. 4, p.185-187, 1995

KRAEMER, M.U.G. et al. The effect of human mobility and control measures on the COVID-19 epidemic in China. Science. eabb4218 25 Mar 2020. doi: https://doi.org/10.1126/science.abb4218

LAN, L.; XU, D.; YE, G. et al Positive RT-PCR Test Results in Patients Recovered From COVID-19. JAMA. Published Online: February 27, 2020. doi: https://doi.org/10.1001/jama.2020.2783

LAUER, S.A. et al. The Incubation Period of Coronavirus Disease 2019 (COVID-19) From Publicly Reported Confirmed Cases: Estimation and Application. Ann Intern Med. 2020; doi: https://doi. org/10.7326/M20-0504

LEWARD, J. A.; LO, N.C. Scientific and ethical basis for social-distancing interventions against COVID-19. The Lancet Infect Dis. Published Online: 23 mar, 2020. doi: https://doi.org/10.1016/ S1473-3099(20)30190-0

LI, Q. et al. A simple laboratory parameter facilitates early identification of COVID-19 patients. medRxiv. 2020.02.13.20022830, 2020a. doi: https://doi.org/10.1101/2020.02.13.20022830 
LI, Q et al. Early transmission dynamics in Wuhan, China, of novel coronavirus-infected pneumonia.

N. Engl. J. Med. 2020b, jan. 29. doi: https://doi.org/10.1056/NEJMoa2001316

LI, Z. et al. Development and Clinical Application of A Rapid IgM-IgG Combined Antibody Test for SARS-CoV-2 Infection Diagnosis J Med Virol. :27 February, 2020. doi: https://doi.org/10.1002/ jmv. 25727

LIU, Y. et al. Clinical and biochemical indexes from 2019-nCoV infected patients linked to viral loads and lung injury. Sci China Life Sci. v. 63, n. 3, p. 364-374, 2020. doi: https://doi.org/10.1007/ s11427-020-1643-8

LU, H. Drug treatment options for the 2019-new coronavirus (2019-nCoV). Biosci Trends. v. 14, n. 1, p. 69-71, 2020. doi: https://doi.org/10.5582/bst.2020.01020

NOVEL CORONAVIRUS PNEUMONIA EMERGENCY RESPONSE EPIDEMIOLOGY TEAM. The epidemiological characteristics of an outbreak of 2019 novel coronavirus diseases (COVID-19) in China. Chin J Epidemiol. v. 41, n. 2, p. 145-151, 2020. doi: https://doi.org/10.3760/cma.j.is sn.0254-6450.2020.02.003

PARMET, W.E.; SINHA, M.S. Covid-19 - The Law and Limits of Quarantine. N. Engl. J. Med. v. 382, e28, 2020. doi: https://doi.org/10.1056/NEJMp2004211

PROMPETCHARA, E. et al. Immune responses in COVID-19 and potential vaccines: Lessons learned from SARS and MERS epidemic. Asian Pac J Allergy Immunol. v. 38, p. 1-9, 2020. doi: https://doi. org/10.12932/AP-200220-0772

REZENDE, J.M. À sombra do plátano: crônicas de história da medicina. São Paulo: Editora Unifesp, 2009. In: - As grandes epidemias da história. pp. 73-82. Disponível em: http://books.scielo.org/ id/8kf92. Acesso em: 31 mar 2020.

SANTOS, I.A.; NASCIMENTO, W. F. As medidas de quarentena humana na saúde pública: aspectos bioéticos. Rev BIOETHIKOS, v. 8, n. 2, p.174-185, 2014.

SHI, S. et al. Association of Cardiac Injury With Mortality in Hospitalized Patients With COVID-19 in Wuhan, China. JAMA Cardiol. Published Online: 25 mar, 2020. doi: https://doi.org/10.1001/ jamacardio.2020.0950

SINGER, P.A. et al. Ethics and SARS: lessons from Toronto. BMJ. v. 327, n. 6, p.1342-1344, 2003. 
SUN, W. et al. The infection evidence of SARS-COV-2 in ocular surface: a singlecenter cross-sectional study. medRxiv. 2020.02.26.20027938, 2020. doi: https://doi. org/10.1101/2020.02.26.20027938

TAN, W. et al. A Novel Coronavirus Genome Identified in a Cluster of Pneumonia Cases - Wuhan, China 20192020[J]. China CDC Weekly. v. 2, n. 4, p. 61-62, 2020. doi: https://doi.org/10.1056/ NEJMoa2001017

THE LANCET. Editorial. COVID-19: learning from experience. The Lancet. v. 395, n. 10229, p. 1101, 2020. doi: https://doi.org/10.1016/S0140-6736(20)30686-3

WANG, D. et al. Clinical Characteristics of 138 Hospitalized Patients With 2019 Novel CoronavirusInfected Pneumonia in Wuhan, China. JAMA. v. 323, n. 11, p. 1061-1069, 2020. doi: https://doi. org/10.1001/jama.2020.1585

\section{WHO. Statement on the second meeting of the International Health Regulations (2005)}

Emergency Committee regarding the outbreak of novel coronavirus (2019-nCoV). 2020a. Disponível em: https://www.who.int/news-room/detail/30-01-2020-statement-on-the-second-meeting-of-theinternational-health-regulations-(2005)-emergency-committee-regarding-the-outbreak-of-novelcoronavirus-(2019-ncov). Acesso em: 25 mar 2020.

WHO. DRAFT landscape of COVID-19 candidate vaccines. 2020b. Disponível em: https://www.who. int/blueprint/priority-diseases/key-action/novel-coronavirus-landscape-ncov.pdf?ua=1. Acesso em: 25 mar 2020.

WILDER-SMITH, A.; FREEDMAN, D.O. Isolation, quarantine, social distancing and community containment: pivotal role for old-style public health measures in the novel coronavirus (2019-nCoV) Outbreak. J Travel Med. v. 27, n. 2, e: taaa020, 2020. doi: https://doi.org/10.1093/jtm/taaa020

WORLDOMETER. Coronavirus. Disponível em: https://www.worldometers.info/coronavirus/. Acesso em: 05 abr 2020.

WU, P. et al. Real-time tentative assessment of the epidemiological characteristics of novel coronavirus infections in Wuhan, China, as at 22 January 2020. Euro Surveill. v. 25, n. 3, pii. 2000044, 2020. doi: https://doi. org/10.2807/1560-7917.ES.2020.25.3.2000044 
XIANG, J. et al. Evaluation of Enzyme-Linked Immunoassay and Colloidal GoldImmunochromatographic Assay Kit for Detection of Novel Coronavirus (SARS-Cov-2) Causing an Outbreak of Pneumonia (COVID-19). medRxiv. 2020.02.27.20028787, 2020. doi: https://doi. org/10.1101/2020.02.27.20028787

ZHANG, B. et al. Clinical characteristics of 82 death cases with COVID-19. medRxiv. 2020.02.26.20028191, 2020. doi: https://doi.org/10.1101/2020.02.26.20028191

ZHANG, J. et al. Therapeutic and triage strategies for 2019 novel coronavirus disease in fever clinics. The Lancet Respir Med. v. 8, n. 3, p. E11-E12, 2020 doi: https://doi.org/10.1016/S22132600(20)30071-0

ZHANG, W. et al. Molecular and serological investigation of 2019-nCoV infected patients: implication of multiple shedding routes. Emerg Microbes Infect. v. 9, n. 1, p. 386-389, 2020. doi: https://doi.org/10.1080/22221751.2020.1729071 
1 Biomédico, Doutor em Ciências; Professor Adjunto do Programa de Pós-graduação em Direito da Universidade Católica de Petrópolis e da Faculdade Nacional de Direito da Universidade Federal do Rio de Janeiro (UFRJ); Perito Criminal - Instituto de Pesquisa e Perícias em Genética Forense /SEPOL. E-mail: rodrigo.grazinoli@ucp.br

2 Bióloga, Doutora em Ciências; Professora Associada do Instituto Três Rios (ITR) e do Programa de Pós-graduação em Práticas em Desenvolvimento Sustentável da Universidade Federal Rural do Rio de Janeiro (UFRRJ).

E-mail: fabiolaitr@gmail.com 